\title{
Release site selection: reintroductions and the habitat concept
}

\author{
Sven Stadtmann and Philip J. Seddon
}

\begin{abstract}
Identifying release sites with good habitat quality is one of the most important steps in any reintroduction project. However, despite their wide application in legislation and research, the habitat concept and habitat-related terms remain poorly defined and subject to confusion. Reviewing a variety of definitions, we advocate for understanding habitat as an area with a species-specific set of resources and environmental conditions that enable a population to persist and reproduce. Using this understanding we investigated release site selection as well as the usage of the term habitat and other habitat-related terms in 324 reintroduction case studies and reintroduction policy documents published during January 1990-May 2016. Although the use of the habitat concept in these publications remained mostly unclear because of the lack of definitions provided, we found an overall improvement in the quality of reintroduction site assessment, and a shift towards more systematic approaches, such as habitat modelling and experimental translocation. To further improve reporting on release site selection, we recommend updating IUCN reintroduction publications and encouraging practitioners to consider the spatial and temporal heterogeneity of habitat, as well as the multiple scales at which a species selects its habitat, in the design of a release site assessment.
\end{abstract}

Keywords Conservation, ecology, habitat, IUCN, reintroduction biology, review, threatened species

Supplementary material for this article is available at https://doi.org/10.1017/So030605318001199.

\section{Species reintroductions and habitat}

$\mathrm{D}$ espite increased international commitment and the expansion of conservation initiatives globally, we are confronted with an ongoing environmental crisis. Habitat degradation, climate change, invasive species and the spread of pathogens are among a range of factors causing an unprecedented loss of both species diversity and abundance (Primack, 2014). Conservation translocations, the deliberate

Sven Stadtmann (Corresponding author) and Philip J. Seddon Department of Zoology, University of Otago, PO Box 56, Dunedin 9054, New Zealand

E-mail sven.stadtmann@postgrad.otago.ac.nz

Received 20 March 2018. Revision requested 3 July 2018.

Accepted 6 September 2018. First published online 23 November 2018. release of organisms into the wild to achieve some conservation benefit (IUCN/SSC, 1987, 2013), are an increasingly common tool to mitigate the effects of biodiversity loss and to restore populations of threatened species (Seddon et al., 2007, 2014). Reintroductions, the conservation translocation of an organism to an area within its indigenous range from which it has disappeared (IUCN/SSC, 2013), are complex and high-risk projects. To improve the chances of success, conservation managers need to address a complex matrix of social, economic and ecological dimensions, and to identify release sites containing high-quality habitat (IUCN/SSC, 2013).

Sufficient knowledge of habitat quality (or the lack of it) is understood to be one of the main factors affecting reintroduction outcomes (Griffith et al., 1989; Kleiman, 1989; Wolf et al., 1996, 1998; Cheyne, 2006; Osborne \& Seddon, 2012), but this understanding does not translate well into practice. For instance, Powell et al. (2012) evaluated the translocation of marten species in the USA and found that although all 51 translocations of American martens Martes americana occurred in what was supposed to be appropriate habitat, only four of the projects reported in detail on the site selection process. Powell et al. (2012) argued that the failure of some projects, in particular those in which the founder animals had been predated, could have been averted if individuals had been released into better quality areas.

In another example, Bennett et al. (2013) investigated the failure of a brown tree creeper Climacteris picumnus release in the Australian Capital Territory and found that, despite experimental habitat restoration measures, the birds had been exposed to predation because of lower foraging habitat quality and lack of refugia, compared to the conditions facing the source population. It is likely that the chances of reintroduction success for this project would have been higher if differences in quality between the release site and the source population's site had been considered in the assessment of the release area.

The importance of habitat has been highlighted not only for terrestrial reintroductions but also for releases in aquatic or riparian ecosystems (e.g. Moorhouse et al., 2009). But what exactly is habitat, and how should we use this term in the context of reintroductions?

\section{The habitat concept}

Habitat is one of the most commonly used concepts in ecology. However, numerous definitions of habitat exist. 
The following list, adapted from Dennis et al. (2003), provides some examples:

(1) Place, living space in which an organism lives (Odlum, 1963)

(2) Type of environment in which an organism lives (Collin, 1988)

(3) The locality, site and particular type of a local environment occupied by an organism (Lincoln et al., 1982)

(4) Place where a species normally lives, often described in terms of physical factors such as topography, and soil moisture and by associated dominant forms (e.g. intertidal rock pools or mesquite woodland); definitions in the ecological literature vary widely but there is consensus for the following: key environment features related to a species; habitat and vegetation classifications may be concordant, but not always so (Calow, 1999)

(5) A suite of resources and environmental conditions that determine the presence, survival and reproduction of a population (Weddell, 2002)

(6) A zone (area) comprising a set of resources, consumables and utilities for the maintenance of an organism (Dennis \& Shreeve, 1996)

(7) A set of resources and environmental conditions that promote occupancy by a species and enable it to persist and reproduce in numbers (Hall et al., 1997; Mathewson \& Morrison, 2013)

Scientists have repeatedly addressed how inconsistently this term has been applied (Elton, 1966; Hall et al., 1997; Dennis et al., 2003; Mathewson \& Morrison, 2013). Calow (1999) argued that linking key environmental features to the distribution of a given species is an inherent part of each definition. However, the existing range of habitat concepts can be divided into two categories: ecological habitat and species-specific habitat.

The term ecological habitat can be used for habitat concepts that describe the features of an environment in which an organism lives, such as geography or a certain vegetation association (Daubenmire, 1968; Rountree \& Able, 2007; see also definitions 1-4 above). Hall et al. (1997) rejected ecological habitat concepts for their confusion with other terms such as biome, and defined habitat as the 'resources and conditions present in an area that produce occupancyincluding survival and reproduction-by a given organism' (Hall et al., 1997). In this case, habitat is species-specific, which implies more than a description of vegetation structures (e.g. Daubenmire, 1968) or topographical features. Instead, the authors focus on the organism and the particular environmental characteristics and resources that it requires to survive and reproduce.

The Hall definition of habitat is closely related to that of the ecological niche (Grinnell, 1917; see also definitions 5-7 above). The niche concept is used to explain the distribution of species, and has developed over time (Elton, 1927; Hutchinson, 1957). Mathewson \& Morrison (2013) emphasized considering the habitat concept in conjunction with a species' niche. The authors found that habitat alone provides only limited insight into biotic interactions and components such as species survival, fitness, or a population's response to a changing environment.

Hall et al. (1997) recommended avoiding referring to 'suitable habitat', as habitat is a binary term in speciesspecific definitions. In other words, an area either is or is not habitat for a given species. If an area does not provide the resources and conditions the species of interest requires, then it is not habitat (Hall et al., 1997). However, a habitat may be unoccupied for various reasons, thus species presence or absence alone is not a good indicator of habitat (Osborne \& Seddon, 2012). For instance, threatened organisms could lack the numbers to colonize all the habitat that is available to them. In the context of reintroduction sites, we suggest using wording such as 'unoccupied habitat' or 'prospective release site' as alternatives.

\section{Habitat and reintroductions}

Before deciding on either a species-specific or ecological habitat concept as a framework for a reintroduction site assessment it is important to consider the way organisms select habitat. Johnson (1980) described this as a hierarchical process with four levels:

(1) Selection of physical or geographical range of a species (a species occupying any space it can reach and survive in)

(2) Placement of home range within the species range

(3) Utilization of habitat components within home range (e.g. identifying foraging sites, shelter)

(4) Micro-selection of resources from the available resources (specific food selection at a foraging site)

Multi-scale models have proven to be effective in making predictions about the habitat selection of a species (Storch, 2003; Store \& Jokimäki, 2003; McGarigal et al., 2016). We recommend adapting these approaches for reintroduction planning to ensure that all levels are being addressed in a release site assessment. However, the decision about the underlying habitat concept can alter the approach for how this might be done.

In an example of how an ecological habitat concept performs under consideration of Johnson's four levels of selection, Prigioni (1995) developed a habitat suitability index to assess the potential for river otter Lutra lutra reintroductions in the Ticino Valley, Italy. He identified 26 habitats in the Ticino Valley and calculated for each a probability of use by river otters. Although Prigioni did not define habitat 
explicitly, terms such as reed thicket and dairy farms, and their identification as individual habitat types, clearly indicate an ecological habitat concept based on vegetation associations (Daubenmire, 1968; Hall et al., 1997). Prigioni did not identify directly the resources within an area that river otters would require (the species-specific approach) but instead categorized structural types of landscape otters could potentially inhabit.

Identifying land cover and vegetative structures that constitute habitat for the species of interest is an important step in a reintroduction site assessment. However, a site assessment based on an ecological habitat definition is coarser than that based on a species-specific approach, and risks overlooking critical microhabitat selection (Johnson's 4th level). Such was the case in Prigioni's (1995) study, in which three levels of habitat selection were addressed.

It is tempting to avoid what could be expensive fieldwork and rather to complete an assessment of habitat only at the third level of selection, using remote sensing and geographical information system tools. However, not all information about a candidate release site can be derived from remote imagery, in particular information about resource quality. Coarse studies at landscape scale are likely to be insufficient to assess a prospective release site fully. In the example of a failed release of tree creepers in Australia (Bennett et al., 2013), the translocation failed because of insufficient knowledge about the release site's microhabitat quality compared to that of the source population. The risk of failure could have been reduced if all levels of selection had been considered in the site assessment.

Including microhabitat in multi-scale habitat assessments is an important reason why we recommend using a speciesspecific definition of habitat, not only in general but particularly in the context of reintroductions. Ecological habitat concepts are too simplistic to address the complexities of the biological world. They ignore the temporal and spatial variation of resources and their contribution to population development, rendering ecological habitat concepts essentially useless for management purposes (Mitchell, 2005; Mathewson \& Morrison, 2013).

The species-specific definition of habitat used by Hall et al. (1997) has already been applied in the context of reintroductions (Armstrong \& Seddon, 2008) and integrates well with the IUCN reintroduction guidelines, in which the target species is already placed at the centre of planning (IUCN/SSC, 2013).

By creating a list of required resources and environmental conditions, planners can identify any gaps in the ecological knowledge about the focal species before assessing potential release sites. If there are too many unknowns, or if the list of requirements is unclear, reliable selection of release sites will not be possible until there is improved understanding of the species-specific habitat features.

\section{Review objectives and literature selection}

The main objective of this review is to improve our understanding of how reintroduction practitioners do and should select quality release sites for threatened species. We retrieved publications using three Web of Science queries: (1) title $=$ reintroduc $c^{\star}$, (2) title $=$ transloc $^{\star}$ AND field $=$ conservation, (3) title $=$ re-introduc ${ }^{\star}$.

We reviewed all papers written in German, French and English. The queries were made in May 2016. In total, 2,920 publications for 1990-2016 were shortlisted by abstract. Of these, 977 were accessible for initial assessment. Based on the abstracts of these publications we determined whether the publication should be shortlisted for use in our review. Three hundred and ninety four of the shortlisted publications were available in full at that time, either as hard copies or for download at the library of Otago University, New Zealand. The availability of publications improved for more recent years because of the increased availability of online repositories. Although it may have been possible to retrieve more papers by contacting external libraries, individuals and publishers, this would have required considerable time and financial resources and would have been unlikely to reveal any patterns or trends not apparent in the core search.

After reading the 394 full publications, we identified 324 items to include in this review. We only considered papers on reintroduction case studies that required a site selection process, and papers from the wider field of reintroduction biology reporting on aspects of release site selection. Seventy publications were disregarded because they did not meet these requirements.

The review addressed two questions: (1) How was the release site selected? (2) How was the term habitat applied? We adapted the 1-4 rating system from Hall et al. (1997): $1=$ excellent, 2 =good, $3=$ moderate, $4=$ poor. A detailed rating key that describes how we rated the publications is provided in Fig. 2. Hall et al. (1997) used these grades to rate the quality of how habitat and habitat-related terms have been used in selected wildlife management publications. We use these grades to rate both the quality of the release site selection process and the use of the habitat concept. The results are presented as trends in mean rating for 1990-2015. We used locally weighted scatterplot smoothing (LOESS) to create trend lines (Cleveland, 1979), and indicate the number of publications per year that were used to create the trend graph. We performed a simple linear regression to measure the strength and direction of any linear relationship between quality of habitat definitions and year, and quality of release site selection and year.

\section{Number of studies per taxonomic group and region}

We collected meta-information on target species and release site region (Fig. 1). Although the number of studies per 
(a) Case studies by region $(n=324)$

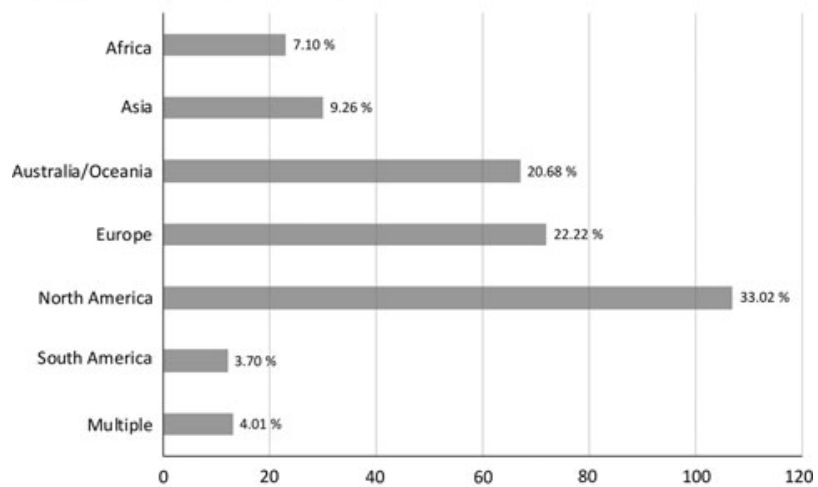

(b) Case studies by taxonomic group $(n=324)$

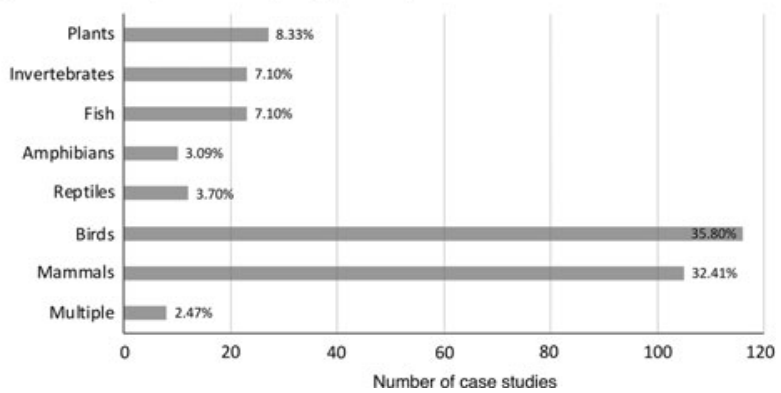

Fig. 1. Number of case studies (a) by region and (b) by taxonomic group, from a total of 324 articles on species reintroductions.

taxonomic group or region was too small to explore trends, the results indicate a taxonomic bias towards studies focusing on birds $(\mathrm{n}=117)$ and mammals ( $\mathrm{n}=106$ species), with both groups providing more case studies than plants, invertebrates, fish, amphibians and reptiles combined $(\mathrm{n}=99)$. This confirms the previously observed bias towards bird and mammal translocation (Seddon, et al., 2005; Bajomi et al., 2010).

The results also indicate a regional bias. The majority of case studies were from more developed regions, such as North America $(n=108)$, Europe $(n=73)$ and Australia/ Oceania $(n=68)$. Only a small number of studies were conducted in regions that encompass developing or threshold countries in Asia, Africa and South America $(n=67)$. This confirms previous summaries of regional reintroduction activities (Seddon et al., 2014).

\section{Types of release site selection}

In the studies reviewed, release sites were selected based on systematic assessments, translocation experiments, expert knowledge and the distribution of a species (Fig. 1). Systematic site assessments include both the creation of habitat models to investigate site quality, and surveys of prospective sites using criteria deemed to be important to the success of the release. For instance, Laws \& Kesler (2012) used Bayesian networks to identify reintroduction (a) Habitat assessment approach and rating $(n=324)$

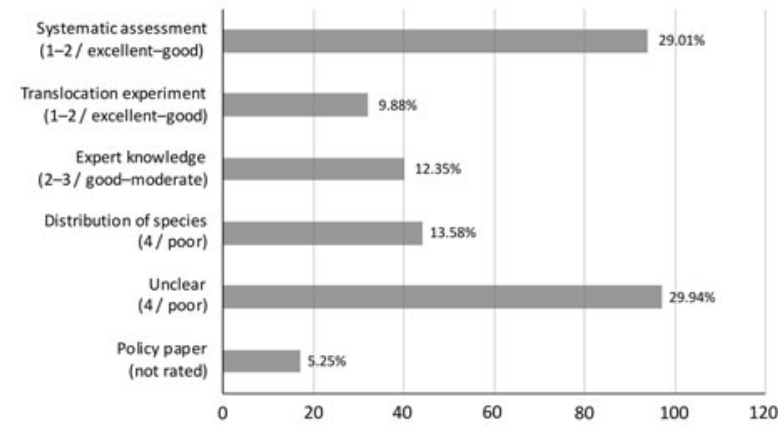

(b) Habitat definition and rating $(n=324)$

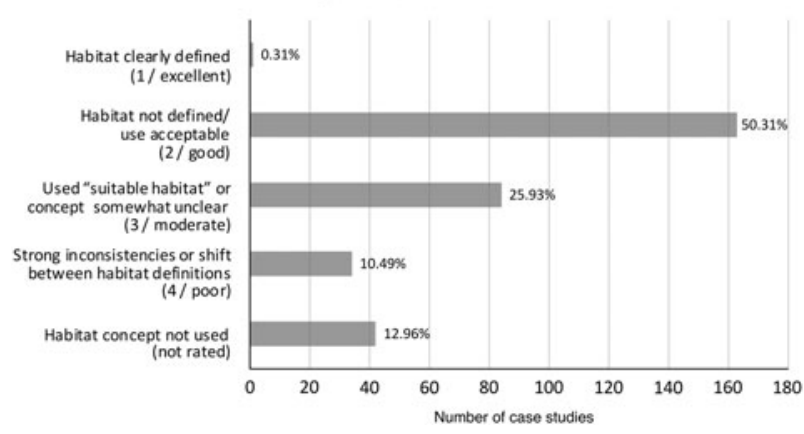

FIG. 2. Number of case studies (a) by site assessment approach and (b) by habitat concept, from a total of 324 papers on species reintroductions. Both the site assessment approach and use of the habitat concept were rated on a scale of $1-4$.

sites for Micronesian kingfishers Todiramphus cinnamominus. Jachowski et al. (2011) investigated the success of reintroduction of black-footed ferrets Mustela nigripes at sites that were selected using habitat criteria including, but not limited to, the density, colony size and number of colonies of prairie dogs Cynomys spp., the ferret's primary prey. Jachowski et al. (2011) also investigated the commitment to monitoring and management, as well as the sociopolitical situation at each site.

Experimental translocations can be applied when ecological knowledge of a species is limited. Rather than trying to establish a persistent population, the main objective of an experimental release is to improve understanding of the habitat requirements of the focal species and its likely overall post-release performance. The information gained can then be used to inform a site selection process. For example, Kuussaari et al. (2015) released clouded Apollo butterflies Parnassius mnemosyne at two sites in Sipoo and Porvoo, Finland, to investigate their ability to establish viable populations on semi-natural grasslands (areas that were previously identified as potential habitat for the species). Lawes et al. (2012) used radio-tagged pygmy rabbits Brachylagus idahoensis at eight sites in southern Oregon to assess homing behaviour and survival (see Gordon, 1996 and Kennedy \& Marra, 2010, for examples from plants and birds, respectively).

Expert knowledge refers to the selection of translocation sites by professionals who have been working with the target 
species for extended periods. Experts usually have in-depth knowledge of a particular conservation topic or species (Store \& Kangas, 2001; Martin et al., 2012) and will have developed a strong intuition for its habitat requirements. For instance, ferruginous ducks Aythya nyroca have been reintroduced at Lake Steinhude (Steinhuder Meer), Germany, under the guidance of experts. The species had been absent from the area for 30 years, but after extensive ecological restoration measures an expert-guided feasibility study identified the area as being suitable for releases (Brandes \& Melles, 2012).

Selection based on information about historical distribution is the simplest form of release site selection, and also potentially the most inaccurate and hence risky. It is not safe to assume that an area that was occupied by a species at some point in the past remains adequate habitat for that species (Osborne \& Seddon, 2012). A change in the ecological conditions of an area may have been a factor in the extirpation of a species from a site. For instance, the South Island takahē Porphyrio hochstetteri, an Endangered New Zealand rail, was once abundant throughout the alpine grasslands of New Zealand. The major cause of its decline has been the introduction of invasive species, including stoats Mustela erminea (Lee \& Jamieson, 2001). The South Island takahë's distribution is currently limited to the Murchison Mountains, a secluded area within the Southern Alps of New Zealand and one of the last places to be invaded by mammalian predators. However, molecular analysis of fossils indicates that the birds were once common throughout most eastern coastal, as well as inland parts of New Zealand's South Island (Grueber \& Jamieson, 2011), with the Murchison Mountains becoming their final refuge. These mountains are characterized by harsh climate and rugged topography that cause high mortality rates as a result of misadventure (A. Digby, pers. comm.). This factor suggests their current range provides less than ideal conditions. Hence, given the low quality of currently occupied areas and a former range overrun by predators, choosing a release site based solely on the takahē's past or present distribution is problematic. A more systematic approach will be required.

\section{Quality of release site selection}

The rating system for the individual types of site assessment is outlined in Fig. 2. The scores for systematic assessments, experiments and expert knowledge could each vary by a grade, depending on the way in which the release site assessment was reported. If the information given was unclear, the paper received the lower of the two ratings.

Although we recommend considering all four levels of an organism's habitat selection in any release site assessment, we did not include in our rating whether a paper addressed them all. Each case study had an individual set of objectives, and we wished to avoid giving a study a lower rating if our
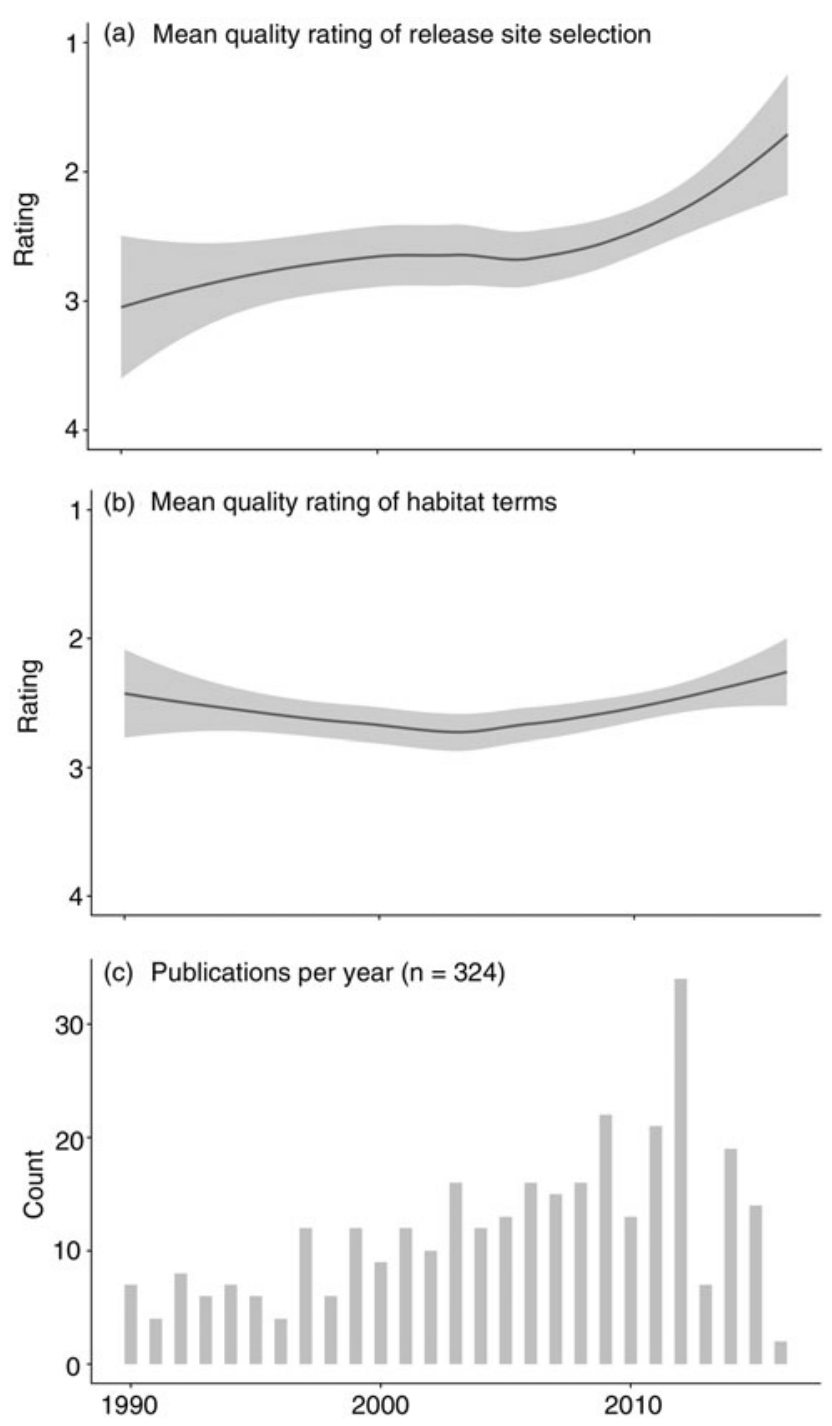

FIG. 3. Mean rating of the quality of (a) release site selection and (b) the use of the term habitat and habitat-related terms in 324 papers on species reintroductions during 1990-2016, with grey shading (from LOESS smoothing) indicating the variance of the data, and (c) the number of publications.

critique was simply beyond the scope of the study. We did, however, include in the rating whether providing additional information on site selection would have been desirable in the context of the publication. The number of studies per assessment category is shown in Fig. 2.

More than half the studies $(n=141)$ received a poor rating because the site selection process was not reported or was based solely on the past distribution of the species. However, the results show an overall improvement in the quality of release site selection between 1990 and 2015 . Although the mean annual rating leaned more towards a moderate grade in earlier years (3.1-2.8), overall, release site selection has improved continuously, towards a good rating of c. 2.o (Fig. 3). Although a lot of unexplained variation remains, this trend is statistically significant $\left(R^{2}=0.03\right.$; 
$\mathrm{P}<0.01$ ). However, although these results indicate a shift towards more systematic assessments, translocation experiments and an overall improvement in recent years, they cannot be used to determine the quality of individual studies.

\section{Use of the habitat concept}

In only one paper was the habitat concept clearly defined (Armstrong \& McLean, 1995); the authors used an ecological habitat definition. In the remaining cases the underlying concept had to be derived from the usage of the word habitat and habitat-related terms. Although in some cases we could identify ecological habitat concepts from terms such as wetland habitats or alpine habitats, it was mostly not possible to categorize the habitat concepts as clearly species-specific or ecological. Without a clear understanding of how the authors used the term habitat we were unable to determine how much the underlying habitat concept might have influenced release site selection. Instead, we focused on checking for inconsistencies in the use of the word habitat and habitat-related terms. Papers were rated as described in Fig. 2 and were included if the authors used the term habitat more than four times. The results do not indicate any significant trend, with a mean rating of 2.4-2.8 during 1990-2015 (Fig. 3), and high variation $\left(R^{2}<0.006, \mathrm{P}=0.28\right)$.

\section{Discussion}

The results of our review indicate a development towards more systematic reintroduction site assessments and we encourage researchers and practitioners to further improve on reporting release site selection. Species translocations require addressing many unknowns (Osborne \& Seddon, 2012), and selecting a release site with high habitat quality will remain one of the most challenging tasks. A comprehensive documentation of these will help inform the design of future translocations.

It is unclear how the use of various habitat concepts may have influenced the site selection approach in the reviewed studies. However, having discussed the shortcomings of ecological habitat concepts, we strongly suggest, under consideration of Johnson's four levels of habitat selection, the application of a species-specific understanding of habitat in the context of reintroductions. A species-specific framework would help researchers and practitioners to identify better the habitat requirements of a species and make it easier to translate these into criteria to investigate during a release site assessment.

Although the IUCN publications such as the Guidelines for Reintroductions and Other Conservation Translocations (IUCN/SSC, 2013) and Global Re-Introduction Perspectives (Soorae, 2016) provide substantial support for the design and implementation of translocation projects, we see potential to include more information on the topic of release site selection within publications, as well as the use of the habitat concept. Therefore, we recommend the following two actions:

(1) Add a section on release site selection to the IUCN Global Re-Introduction Perspectives template: this series provides overviews of species reintroduction projects following comprehensive reporting standards (Soorae, 2016). Including a section on release site assessments for each case study would be an opportunity to provide additional insights into reintroduction planning and feasibility studies for a wide audience of researchers and practitioners.

(2) Define habitat in any future revisions of the IUCN/SSC reintroduction guidelines: a possible source of confusion about the term habitat could be that ecological habitat concepts are commonly used by governmental institutions in policy documents and legislation (Mathewson \& Morrison, 2013; see also Shears, 2007). IUCN uses a habitats classification scheme for the IUCN Red List to describe vegetation associations. This has been partly adapted from the classification scheme of the Ramsar Convention on Wetlands (IUCN, 2012; The Ramsar Convention on Wetlands, 2018), which uses the ecological habitat concept.

The application of species-specific habitat concepts for reintroductions has already been introduced (Armstrong \& Seddon, 2008; Osborne \& Seddon, 2012) and the IUCN reintroduction guidelines, although they do not provide a clear definition of the terms, promote the use of a speciesspecific habitat concept. This creates a potential conflict in key definitions between IUCN policy outputs. We recommend that any update of the IUCN reintroduction guidelines addresses this issue and includes a section on the species-specific definition of habitat, outlining why this is the preferred definition for reintroduction biology.

We invite researchers and practitioners to consider the eight consequences for selecting release sites, introduced by Osborne \& Seddon (2012). In his seminal paper, Southwood (1977) viewed habitat in a species-specific context of spatial and temporal heterogeneity, finding that habitat, as well as a species' adaptation to habitat, can vary and change over time. These are aspects that need to be considered during a release site assessment. Osborne \& Seddon (2012) translated Southwood's findings into the following eight consequences for reintroductions.

(1) Historical locations of a species' presence may not indicate present-day habitat.

(2) Present-day locations of a species' presence may not indicate habitat of good quality.

(3) Present-day locations where a species is absent may not indicate habitat of low quality. 
(4) Present-day locations of a species' presence may not indicate a suitable future habitat.

(5) Not all quality habitat patches will be colonized because the landscape components may be missing.

(6) A habitat's quality and its characteristics vary across the species' range.

(7) Individuals from across a species' range may not all be equally suited to the chosen release site.

(8) A habitat of good quality may need to be engineered (restored or created) to aid colonization and then managed to maintain its perceived value. The complexity of doing this is often not appreciated.

These provide a framework for the design of site assessments and are based on a simple maxim: release sites should neither be selected just because the target species used to be there, nor just because the site looks right (Osborne \& Seddon, 2012).

The first four consequences can be addressed simply by avoiding the temptation to use the distribution of a species as the sole criterion for release site selection. We have discussed the shortcomings of this method using the South Island takahē as an example. However, that does not mean the distribution of the species has no relevance or usefulness in the site selection process. For instance, Seidel et al. (1998) used the historical range of lynx Lynx lynx populations in the southern Rocky Mountains as a deterministic criterion for the identification of reintroduction sites by excluding all sites outside their former range within the Rocky Mountains. However, the authors concluded that a survey of both current vegetation associations, and the abundance of snowshoe hare Lepus americanus populations as an important part of the lynx's diet, would be necessary to identify good release sites within the species' former range.

Regarding the sixth consequence (a habitat's suitability and its characteristics vary across the species range), a species' habitat is usually more diverse and less favourable at its periphery, compared to the core range (Channell \& Lomolino, 2000). Consequently, individuals that utilize the periphery of a range usually have lower survival rates and reduced reproductive success (Carrascal \& Seoane, 2009). To avoid overestimating the quality of a release site by comparing it against low-quality peripheral parts of a range, we recommend developing an understanding of habitat as a species-specific set of resources and environmental conditions. In doing so, the most important question to be asked would be: which individuals across the population distribution have the highest productivity, and why? The answer to this question could come from something as simple as creating a list of the resources and environmental conditions that are correlatives of high productivity. If the habitat requirements were unclear, this would greatly increase the risk for the reintroduction project and one should seek to improve ecological knowledge before attempting the reintroduction, or to design the translocation as an experiment. The set of resources and environmental conditions will ultimately inform how the species of interest selects habitat, and should translate into the criteria that need to be considered in a multi-scale site assessment. Using this approach the assessment addresses both species-specific habitat selection and the variability of a prospective release site.

The seventh consequence (individuals from across a species range may not all be equally suited to the chosen release site) concerns both the choice of the source population for the translocation, and the selection of the release site. Individuals derived from wild populations can be better suited as founders at a new site, compared to captive-bred conspecifics (Jule et al., 2008). However, a species can also encompass a variety of genotypes and phenotypes (Blondel et al., 2006), and as a result there may be parts of its distribution that cannot be utilized by all individuals. This can also be a response to the variation in habitat quality across a species' range, as addressed in consequence 6 . The release site should therefore be compared only to the habitat of those populations or individuals that are suitable founders for the reintroduction.

Following from consequences $1-7$, a release site may be engineered, ecologically restored and managed continuously to provide adequate habitat for a population to grow and persist (Osborne \& Seddon, 2012). For instance, the South Island takahe population in the Murchison Mountains of New Zealand is supported by intensive predator control (Birmingham, 2018), which keeps the population of invasive mammals at sufficiently low levels for takahè to persist. However, the example of the brown tree creeper shows that even ecological improvements (in this case the provision of tree holes) do not guarantee the survival of a reintroduced population if the importance of other habitat criteria has been underestimated (Bennett et al., 2013).

\section{Conclusion}

In July 2018 the disastrous outcome of a translocation of black rhinoceroses Diceros bicornis to Tsavo East National Park, Kenya, was reported (The Guardian, 2018). It is now confirmed that all 11 individuals released in the Park have died, and thus more rhinoceroses were killed in a single translocation than by poachers in the area in recent years. The cause of death for at least nine individuals was found to be saltwater poisoning (Save the Rhino, 2018): water quality appears to have been overlooked in the habitat assessment.

This tragedy demonstrates the risks of species translocations and highlights our main point: there can be no compromise when investigating habitat quality. The best release site assessments still bear a moderate risk of overlooking important habitat criteria, whereas releasing wildlife in an area that simply looks good is extremely risky. We 
are aware of the financial challenges facing many conservation projects but we urge reintroduction practitioners to consider qualitative and systematic habitat assessments and to accept the high costs of these approaches, including the necessity of extensive fieldwork before translocation, as an essential part of any translocation project. These investments are necessary to reduce the risk of the translocation and to ensure the best possible outcome. We hope that this understanding will soon translate into reintroduction policy documents and the production of more comprehensive habitat assessment protocols as part of project and research outputs.

We sought here to improve the understanding of the requirements for selecting quality reintroduction sites, and to address some inconsistencies in the use of the habitat concept as applied to reintroductions. We hope our findings will be of use for researchers and practitioners alike, and that the information provided can help reduce the number of unknown factors in the design of systematic translocation site assessments. We believe that putting the species and its requirements at the centre of the site assessment is the most effective way to address the many unknown aspects of a reintroduction project. A full bibliography of the case studies is available in Supplementary Material 1, and the raw data of this study are available on request.

Acknowledgements We thank Martin Fisher and two anonymous reviewers for their valuable comments.

Author contributions Study design, data collection and analysis, writing: SST; guidance and supervision of the research process, revision: PJS.

\section{Conflicts of interest None.}

Ethical standards This research complied with the Oryx Code of Conduct for authors.

\section{References}

Armstrong, D.P. \& McLean, I. (1995) New Zealand translocations: theory and practice. Pacific Conservation Biology, 2, 39-54.

Armstrong, D.P. \& Seddon, P.J. (2008) Directions in reintroduction biology. Trends in Ecology \& Evolution, 23, 20-25.

Bajomi, B., Pullin, A.S., Stewart, G.B. \& Takács-Sánta, A. (2010) Bias and dispersal in the animal reintroduction literature. Oryx, 44, $358-365$.

Bennett, V.A., Doerr, V.A., Doerr, E.D., Manning, A.D., Lindenmayer, D.B. \& Yoon, H.-J. (2013) Causes of reintroduction failure of the brown treecreeper: implications for ecosystem restoration. Austral Ecology, 38, 700-712.

Birmingham, C. (2018) Department of Conservation, Murchison Mountains Annual Report, Fiordland National Park 2016/2017. Unpublished report. Department of Conservation NZ, Te Anau, New Zealand.

Blondel, J., Thomas, D.W., Charmantier, A., Perret, P., Bourgault, P. \& Lambrechts, M.M. (2006) A thirty-year study of phenotypic and genetic variation of blue tits in Mediterranean habitat mosaics. BioScience, 56, 661-773.
Brandes, F. \& Melles, F. (2012) Wiederansiedlung der Moorente am Steinhuder Meer-ein Beitrag zoologischer Einrichtungen zum Artenschutz in Deutschland. Zeitschrift Des Kölner Zoos, 55, 155-163.

CALOw, P.P. (1999) Blackwell's Concise Encyclopedia of Ecology. Wiley-Blackwell, Hoboken, USA.

Carrascal, L.M. \& Seoane, J. (2009) Linking density, productivity and trends of an endangered species: the Bonelli's eagle in Spain. Acta Oecologica, 35, 341-348.

Channell, R. \& Lomolino, M.V. (2000) Dynamic biogeography and conservation of endangered species. Nature, 403, 84-86.

Cheyne, S.M. (2006) Wildlife reintroduction: considerations of habitat quality at the release site. BMC Ecology, 6, 5 .

Cleveland, W.S. (1979) Robust locally weighted regression and smoothing scatterplots. Journal of the American Statistical Association, 74, 829-836.

Collin, P.H. (1988) Dictionary of Ecology and the Environment. Peter Collin Publishing, Teddington, UK.

Daubenmire, R. (1968) Plant Communities. Harper \& Row, New York, USA.

Dennis, R.L.H. \& Shreeve, T.G. (1996) Butterflies on British and Irish Offshore Islands. Gem Publishing Co., Phoenix, USA.

Dennis, R.L.H., Shreeve, T.G. \& Van Dyck, H. (2003) Towards a functional resource-based concept for habitat: a butterfly biology viewpoint. Oikos, 102, 417-426.

Elton, C.S. (1927) Animal Ecology. Macmillan, New York, USA.

Elton, C.S. (1966) The Pattern of Animal Communities. Elsevier, Dordrecht, Netherlands.

Gordon, D.R. (1996) Experimental translocation of the endangered shrub Apalachicola rosemary Conradina glabra to the Apalachicola Bluffs and Ravines Preserve, Florida. Biological Conservation, 77, 19-26.

Griffith, B., Scott, J.M., Carpenter, J.W. \& Reed, C. (1989) Translocation as a species conservation tool: status and strategy. Science, 245, 477-480.

Grinnell, J. (1917) The niche-relationships of the California thrasher. The Auk, 34, 427-433.

Grueber, C.E. \& Jamieson, I.G. (2011) Low genetic diversity and small population size of takahe Porphyrio hochstetteri on European arrival in New Zealand. Ibis, 153, 384-394.

Hall, L.S., Krausman, P.R. \& Morrison, M.L. (1997) The habitat concept and a plea for standard terminology. Wildlife Society Bulletin, 25, 173-182.

Hutchinson, G.E. (1957) Concluding remarks. Cold Spring Harbor Symposia on Quantitative Biology, 22, 415-427.

IUCN (2012) IUCN Habitats Classification Scheme. Version 3.1. IUCN, Gland, Switzerland.

IUCN/SSC (1987) The IUCN Position Statement on Translocation of Living Organisms. IUCN, Gland, Switzerland.

IUCN/SSC (2013) Guidelines for Reintroductions and Other Conservation Translocations. Version 1.o. IUCN/SSC Reintroduction Specialist Group, Gland, Switzerland.

Jachowski, D.S., Gitzen, R.A., Grenier, M.B., Holmes, B. \& Millspaugh, J.J. (2011) The importance of thinking big: large-scale prey conservation drives black-footed ferret reintroduction success. Biological Conservation, 144, 1560-1566.

Johnson, D.H. (1980) The comparison of usage and availability measurements for evaluating resource preference. Ecology, 61, 65-71.

Jule, K.R., Leaver, L.A. \& Lea, S.E.G. (2008) The effects of captive experience on reintroduction survival in carnivores: a review and analysis. Biological Conservation, 141, 355-363.

Kennedy, C.M. \& Marra, P.P. (2010) Matrix mediates avian movements in tropical forested landscapes: inference from experimental translocations. Biological Conservation, 143, 2136-2145. 
Kleiman, D.G. (1989) Reintroduction of captive mammals for conservation-guidelines for reintroducing endangered species into the wild. BioScience, 39, 152-161.

Kuussaari, M., Heikkinen, R.K., Heliölä, J., Luoto, M., Mayer, M., RYtTERI, S. \& VON BAGH, P. (2015) Successful translocation of the threatened clouded Apollo butterfly (Parnassius mnemosyne) and metapopulation establishment in southern Finland. Biological Conservation, 190, 51-59.

Lawes, T.J., Anthony, R.G., Robinson, W.D., Forbes, J.T. \& LorTon, G.A. (2012) Homing behavior and survival of pygmy rabbits after experimental translocation. Western North American Naturalist, 72, 569-581

Laws, R.J. \& KesleR, D.C. (2012) A Bayesian network approach for selecting translocation sites for endangered island birds. Biological Conservation, 155, 178-185.

Lee, W.G. \& Jamieson, I.G. (2001) Introduction. In The Takahe (eds W.G. Lee \& I.G. Jamieson), pp. 11-17. University of Otago Press, Dunedin, New Zealand.

Lincoln, R.J., Boxshall, G.A. \& Clark, P.F. (1982) A Dictionary of Ecology, Evolution and Systematics. Cambridge University Press, Cambridge, UK.

Martin, T.G., Burgman, M.A., Fidler, F., Kuhnert, P.M., LowChoy, S., McBride, M. \& Mengersen, K. (2012) Eliciting expert knowledge in conservation science. Conservation Biology, 26, 29-38.

Mathewson, H.A. \& Morrison, M.A. (2013) The misunderstanding of habitat. In Wildlife Habitat Conservation (eds M.L. Morrison \& H.A. Mathewson), pp. 3-9. Johns Hopkins University Press, Baltimore, USA.

McGarigal, K., Wan, H.Y., Zeller, K.A., Timm, B.C. \& Cushman, S.A. (2016) Multi-scale habitat selection modeling: a review and outlook. Landscape Ecology, 31, 1161-1175.

Mitchell, S.C. (2005) How useful is the concept of habitat? - a critique. Oikos, 110, 634-638.

Moorhouse, T.P., Gelling, M. \& Macdonald, D.W. (2009) Effects of habitat quality upon reintroduction success in water voles: evidence from a replicated experiment. Biological Conservation, 142, $53-60$

ODlum, E.P. (1963) Ecology. Holt, Rinehart \& Winston, New York, USA

Osborne, P.E. \& Seddon, P.J. (2012) Selecting suitable habitats for reintroductions: variation, change and the role of species distribution modelling. In Reintroduction Biology (eds J.G. Ewen, D.P. Armstrong, K.A. Parker \& P.J. Seddon), pp. 73-104. John Wiley \& Sons, Ltd, Chichester, UK.

Powell, R.A., Lewis, J.C., Slough, B.G., Brainerd, S.M., Jordan, N.R., Aвramov, A.V. et al. (2012) Evaluating translocations of martens, sables and fishers: testing model predictions with field data. In Biology and Conservation of Martens, Sables and Fishers A New Synthesis (eds K.B. Aubry, W.J. Zielinski, M.G. Raphael, G. Proulx \& S.W. Buskirk), pp. 93-137. Cornell University Press, Ithaca, USA.

Prigioni, C. (1995) Guidelines for the feasibility study of reintroduction of the otter Lutra lutra in Italy: the project of the Ticino valley (north-western Italy). Hystrix, 7, 255-264.

PrimaCK, R.B. (2014) Essentials of Conservation Biology. 4th edition. Sinauer Associates, Sunderland, USA.
Rountree, R.A. \& Able, K.W. (2007) Spatial and temporal habitat use patterns for salt marsh nekton: implications for ecological functions. Aquatic Ecology, 41, 25-45.

Save the Rhino (2018) All rhinos translocated to Tsavo East National Park have died. Https://www.savetherhino.org/africa/kenya/allrhinos-translocated-to-tsavo-east-national-park-have-died/ [accessed 7 August 2018].

Seddon, P.J., Soorae, P.S. \& Launay, F. (2005) Taxonomic bias in reintroduction projects. Animal Conservation, 8, 51-58.

Seddon, P.J., Armstrong, D.P. \& Maloney, R.F. (2007) Developing the science of reintroduction biology. Conservation Biology, 21, 303-312.

Seddon, P.J., Griffiths, C.J., Soorae, P.S. \& Armstrong, D.P. (2014) Reversing defaunation: restoring species in a changing world. Science, 345, 406-412.

Seidel, J., Andree, B., Berlinger, S., Buell, K., Byrne, G., Gill, B. et al. (1998) Draft Strategy for the Conservation and Reestablishment of Lynx and Wolverine in the Southern Rocky Mountains. USDA Forest Service, Fort Collins, USA.

Shears, N.T. (2007) Biogeography, Community Structure and Biological Habitat Types of Subtidal Reefs on the South Island West Coast, New Zealand. Science \& Technical Publishing, Department of Conservation, Wellington, New Zealand.

Soorae, P.S. (2016) Global Re-introduction Perspectives: 2016. Case-Studies From around the Globe. IUCN/SSC Reintroduction Specialist Group and Environment Agency-Abu Dhabi, Gland, Switzerland and Abu Dhabi, United Arab Emirates.

Southwood, T.R. (1977) Habitat, the templet for ecological strategies? Journal of Animal Ecology, 46, 337-365.

STORCH, I. (2003) Linking a multiscale habitat concept to species conservation. In Landscape Ecology and Resource Management (eds J.A. Bissonette \& I. Storch), pp. 303-320. Island Press, Washington, DC, USA.

StORE, R. \& JOKIMÄKI, J. (2003) A GIS-based multi-scale approach to habitat suitability modeling. Ecological Modelling, 169, 1-15.

STORE, R. \& KANGAS, J. (2001) Integrating spatial multi-criteria evaluation and expert knowledge for GIS-based habitat suitability modelling. Landscape and Urban Planning, 55, 79-93.

The Guardian (2018) Eight of 14 rhinos die after move to Kenyan national park. Https://www.theguardian.com/world/2018/jul/13/ kenya-rhinos-die-after-being-moved-between-national-parks [accessed 7 August 2018].

The Ramsar Convention on Wetlands (2018) Draft Resolution on Promoting the Conservation and Wise Use of Intertidal Wetlands and Ecologically Associated Habitats. Https://www.ramsar.org/ document/sc54-2113-draft-resolution-on-promoting-theconservation-and-wise-use-of-intertidal [accessed 1 March 2018].

Weddell, B.J. (2002) Conserving Living Natural Resources. Cambridge University Press, Cambridge, UK.

Wolf, C.M., Griffith, B., Reed, C. \& Temple, S.A. (1996) Avian and mammalian translocations: update and reanalysis of 1987 survey data. Conservation Biology, 10, 1142-1154.

Wolf, C.M., Garland, JR, T. \& Griffith, B. (1998) Predictors of avian and mammalian translocation success: reanalysis with phylogenetically independent contrasts. Biological Conservation, 86, 243-255. 